\title{
Analisis Pelaksanaan Sasaran Keselamatan Pasien Oleh Perawat Di Rumah Sakit
}

\author{
tasyahalawa1705@gmail.com
}

\section{Latar Belakang}

Keselamatan (safety) menjadi isu global termasuk di rumah sakit. Rumah sakit wajib mengupayakan pemenuhan sasaran keselamatan pasien yang diatur dalam Peraturan Menteri Kesehatan nomor 11 tahun 2017. Rumah Sakit merupakan institusi pelayanan kesehatan bagi masyarakat dengan karakteristik tersendiri yang dipengaruhi oleh perkembangan ilmu pengetahuan kesehatan, kemajuan teknologi dan kehidupan sosial ekonomi masyarakat. menjelaskan bahwa seluruh kegiatan pelayanan dirumah sakit harus memberikan pelayanan yang memenuhi standar kualitas serta jaminan rasa aman dan perlindungan terhadap dampak pelayanan yang diberikan dalam rangka memenuhi hak-hak masyarakat akan pelayanan yang berkualitas serta aman. Dalam hal ini rumah sakit melaksanakan program-program mutu dan keselamatan pasien. Keselamatan pasien rumah sakit adalah suatu sistem dimana rumah sakit membuat asuhan pasien lebih aman dengan mencegah terjadinya cedera yang disebabkan oleh kesalahan akibat melaksanakan suatu tindakan atau tidak mengambil tindakan yang seharusnya diambil. Budaya keselamatan pasien di suatu rumah sakit dapat diketahui dengan melakukan kajian evaluasi yaitu untuk mengetahui seberapa jauh budaya keselamatan pasien di suatu rumah sakit.

Rumah sakit merupakan salah satu institusi pelayanan kesehatan profesional yang sangat kompleks karena ada padat modal, padat teknologi, padat karya, padat profesi, pada sistem, dan padat mutu serta pada risiko sehingga sangat memungkinkan terjadi kejadian tidak diinginkan (KTD) yang dapat berakibat pada terjadinya cedera bahkan sampai dengan kematian pasien. Dalam upaya meminimalisir terjadinya kesalahan akibat melaksanakan suatu tindakan atau tindakan yang seharusnya tidak diambil terkait dengan aspek keselamatan 
pasien dan kualitas rumah sakit, maka sangat diperlukan pentingnya membangun budaya keselamatan pasien. Budaya keselamatan pasien adalah nilai nilai, sikap, persepsi kompetensi dan pola perilaku dari individu yang menentukan komitmen dan gaya kemampuan manajemen rumah sakit dalam meminimalkanpajanan yang membahayakan atau mencelakakan karyawan, manajemen pasien, atau anggota masyarakat lainnya.

\section{Metode}

Penelitian ini penulis untuk mendeskripsikan seluruh pelaksanaan Analisis Pelaksanaan Sasaran Kesehatan di Rumah inpeksi K3 merupakan upaya deteksi dini dan mengoreksi adanya potensi di tempat kerja yang dapat menimbulkan kecelakaan, inspeksi tempat kerja bertujuan untuk mengidentifikasi sumber sumber bahaya potensial yang ada di tempat kerja, mengevaluasi tingkat resiko terhadap tenaga kerja serta mengendalikan sampapi tingkat yang aman bagi kesehatan dan keselamatan tenaga kerja.

Dari hasil pencarian kemudian diolah dan dianalisis sehingga menghasilkan sebuah pembahasan dan kesimpulan dari topik yang ditetapkan. Pengukuran Analisis Pelaksanaan Sasaran Kesehatan di Rumah dipengaruhi oleh sikap aman dan tidak aman pegawai di level individu, unit kerja Secara khiusus di level manajemen senior dalam hal kepemimpinan transformasional yang berbagai penelitian tentang budaya menunjukkan bahwa kepemimpinan transformasional sangat berpengaruh dalam membangun suatu budaya Keberhasilan penerapan keselamatan pasien ini menjadi tanggung jawab seluruh komponen dalam rumah sakit termasuk perawat. Perawat merupakan tenaga kesehatan yang selalu mendampingi pasien sehingga sangat berisiko melakukan kelalaian yang dapat menyebabkan pasien cedera.

\section{Hasil}

Berdasarkan hasil pencarian literatur di dapatkan peran perawat dalam penerapan sasaran keselamatan pasien di rumah sakit, dimana di dalam literature 
review terebut penelitian ini mendapatkan hasil bahwa perawat memiliki peran penting dalam menerapkan sasaran keselamatan pasien di rumah sakit untuk menjaga pasien dari suatu kecelakaan yang tidak di inginkan selama pasien tersebut berada di rumah sakit oleh karena itu sasaran keselamatan pasien harus di jalankan di RS.

Analisa Penerapan sasaran kesehatana keselamatan K3 di Rumah Sakit menunjukkan bahwa, dengan adanya kebijakan terkait K3 di rumah sakit maka budaya K3 akan lebih baik Kinerja merupakan tingkat keberhasilan seseorang secara keseluruhan dalam periode tertentu didalam melaksanakan tugas dibanding dengan berbagai kemungkinan seperti standart hasil kerja, target, sasaran atau kriteria yang telah ditentukan terlebih dahulu dan telah disepakati bersama. Hal ini dapat tercapai apabila perusahaan selalu memperhatikan faktor keselamatan dan kesehatan kerja (K3) karena hal ini akan dapat meningkatkan kinerja karyawan. Perhatian terhadap kesehatan pekerjaan pada mulanya lebih menekankan pada masalah keselamatan kerja yaitu perlindungan pekerjaan dari kerugian atau luka yang disebabkan oleh kecelakaan berkaitan dengan kerja.

faktor faktor yang menjadi tantangan bagi perawat dakam memberikan keperawatan yang aman dan memberikan kontribusi dalam keselamatan pasien salah satunya adalah kerja sama tim kinerja kerja sama tim yang terganggu juga merupakan salah satu penyebab insiden keselamatan pasien yang merupakan kombinasi dari kegagalan sitem. Tingkat Pengetahuan Tingkat pengetahuan tenaga medis khususnya perawat sangatlah penting dalam meiaksanakan asuhan keperawatan. Semakin tinggi pengetahuan perawat tentang kode etik dan hukum kesehatan maka semakin baik pula kinerja perawat dalam melaksanakan asuhan keperawatan.

Perawat dan pasien seharusnya diperlakukan secara adil ketika terjadi insiden. Ketika terjadi insiden, selayakanya tidak terfokus untuk mencari kesalahan individu tetapi lebih mempelajari secar sistem yang menagkibatkan terjadinya kesalahan Budaya tidak menyalahkan pada kepada perawat perlu dikembangkan dalam menumbuhkan budaya keselamatan pasien. Insiden keselamatan pasien adalah suatu sistem untuk mendokumentasikan laporan 
insiden keselamatan pasien, analisis dan solusi untuk pembelajaran Budaya tidak menyalahkan pada kepada perawat perlu dikembangkan dalam menumbuhkan budaya keselamatan pasien.

Keberhasilan penerapan keselamatan pasien ini menjadi tanggung jawab seluruh komponen dalam rumah sakit termasuk perawat. Perawat merupakan tenaga kesehatan yang selalu mendampingi pasien sehingga sangat berisiko melakukan kelalaian yang dapat menyebabkan pasien cedera Untuk mengurangi jumlah pasien jatuh sebaiknya para petugas di rumah sakit berkolaborasi untuk memberikan pelayanan yang lebih baik kepada pasien dan melaksanakan tindakan sesuai dengan SOP.

Pelaksanaan sasaran keselamatan pasien di rumah sakit dilihat daripendekatan sistem, pada komponen input kebijakan dan SPO sudah ada, namun tenaga, metode, dana dan sarana masih belum memenuhi syarat. Pada komponen proses, pelaksanaan enam sasaran keselamatan pasien di rumah sakit masih belum mencapai standar, karena dalam pelaksanaannya belum menjadi budaya bagi petugas. Dan pada komponen output, pencapaian target kepatuhan petugas dalam pelaksanaan sasaran keselamatan pasien di rumah sakit belum menunjukkan hasil yang diharapkan.

\section{Pembahasan}

Keselamatan pasien merupakan prioritas utama dalam pelayanan kesehatan dirumah sakit. dan hal itu terkait dengan isu mutu dan citra rumah sakit. Oleh harena itu implementasi sistem manajemen mutu dengan meningkatkan keselamatan pasien "patient safety" diharapkan dapat menurunkan angka kematian akibat cedera medis dengan membangun dan membudayakan keselamatan pasien di rumah sakit dengan menerapkan sasaran keselamatan pasien . Keselamatan adalah suatu sistem yang membuat asuhan pasien lebih aman, meliputi asasmen risiko, identifikasi dan pengelolaan risiko pasien, pelaporan dan analisis insiden, kemampuan belajar dari insiden dan tindak lanjutnya, serta implementasi solusi untuk meminimalkan timbulnya risiko dan 
mencegah terjadinya cedera yang disebabkan oleh kesalahan akibat melaksanakan suatu tindakan atau tidak mengambil tindakan yang seharusnya.

Salah satu prinsip pelayanan kesehatan adalah menyelamatkan pasien dengan prosedur dan tindakan yang aman dan tidak membahayakan pasien maupun petugas pemberi pelayanan kesehatan. Setiap fasilitas layanan kesehatan harus selalu menjaga keamanan proses pelayanan kesehatannya guna menghindari terjadinya kesalahan medis (medical error) yang bisa berpengaruh terhadap kualitas pelayanan kesehatan.Keselamatan pasien merupakan suatu upaya menjamin segala tindakan dan aktivitas yang berhubungan dengan pasien yang dilakukan oleh petugas kesehatan agar berlangsung dengan aman dan tidak menimbulkan efek atau dampak yang membahayakan bagi pasien melalui serangkaian aktivitas yang telah diatur dalam perundang-undangan.

Peningkatan mutu merupakan suatu proses pengukuran derajat kesempurnaan pelayanan kesehatan dibandingkan dengan standar atau prinsip dengan tindakan perbaikan yang sistematik dan berkesinambungan untuk mencapai mutu pelayanan yang optimum atau prima sesuai dengan standar ilmu pengetahuan dan teknologi serta kemampuan sumber daya yang ada. Kualitas atau mutu pelayanan kesehatan tidak dapat lepas dari kepuasan pelanggan atau pasien. Pelayanan kesehatan yang bermutu dapat meningkatkan kepuasan pasien terhadap pelayanan yang diberikan. Selain itu, kepuasan pasien dapat dijadikan tolok ukur keberhasilan mutu pelayanan sebuah fasilitas kesehatan. Kepuasan pasien akan tercipta ketika apa yang didapat lebih besar dari yang diharapkan.

Sasaran keselamatan pasien meliputi tercapainya hal-hal sebagai berikut: 1) Ketepatan identifikasi pasien; 2) Peningkatan komunikasi yang efektif; 3) Peningkatan keamanan obat-obatan yang harus diwaspadai; 4) Kepastian lokasi pembedahan pada pasien yang benar; 5) Pengurangan risiko infeksi terkait pelayanan kesehatan; 6) Pengurangan risiko cedera pasien akibat terjatuh. Maksud dari sasaran keselamatan pasien adalah mendorong perbaikan spesifik dalam keselamatan pasien yang menyoroti bidang-bidang bermasalah dalam perawatan kesehatan, memberikan bukti dan solusi hasil konsensus yang berdasarkan nasihat para pakar. melaksanakan SPO pencegahan pasien resiko jatuh. Karena 
keselamatan pasien merupakan prioritas utama untuk dilaksankan di rumah sakit dan hal itu terkait dengan isu mutu dan citra rumah sakit.

Isu keselamatan pasien melahirkan paradigma baru tentang mutu pelayanan. Mutu pelyanan yang baik saja tidak cukup berarti bagi pasien tanpa memperhatikan bagaimana derajat unsur resiko dan keselamatan yang diterima oleh pasien. Tinggi rendahnya mutu sebanding dengan tingkat ketersediaan fasilitas pelayanan, untuk mencapai keseimbazngan terbaik antara risiko dan manfaat keselamatan yang diterima oleh pasien. Sarana prasarana untuk mengurangi risiko pasien cedera akibat jatuh di ruang rawat inap rumah sakit sudah sesuai dengan standar. Di bangsal pasien dan kamar mandi sudah terpasang handrail. Seluruh tempat tidur pasien sudah memiliki besi pengaman dan tersedia segitiga kuning yang digantung di tempat tidur pasien yang berisiko jatuh. Hal yang berbeda dengan ruangan rawat inap non Bedah dimana belum ada satupun terpasang handrail, sehingga kemungkinan kejadian risiko jatuh cukup tinggi.

Kendala dalam pelaksanaan sasaran keselamatan pasien dipengearuhi oleh kurangnya sosialisasi, motivasi, pengawasan, dukungan dari manajemen rumah sakit. kurangnya pengawasan dalam pelaporan insiden keselamatan pasien (KTD, KPC, KNC). Salah satu cara untuk menilai dampak ini adalah membandingkan status akreditasi dengan ukuran kualitas berbasis bukti lainnya, seperti langkahlangkah proses yang sekarang dilaporkan dengan pelaksanaan secara berkesinambungan. dapat disimpulkan bahwa supervisi merupakan aktivitas yang harus rutin dilakukan guna mencapai implementasi sasaran keselamatan pasien yang lebih optimal sehingga keselamatan pasien akan menjadi prioritas pada setiap aktivitas dan penerapannya menjadi budaya yang harus dilakukan oleh seluruh perawat tanpa terkecuali pelaksanaan supervisi yang kurang baik berdampak pada pelaksanaan sasaran keselamatan pasien walauapun kategori baik pada pelaksanaan identifikasi, komunikasi, kemanan obat, tepat prosedur, lokasi, pasien operasi tetapi pelaksanaan pengurangan risiko infeksi dan risiko pasien jatuh belum maksimal. 
Sarana dan prasarana keselamatan pasien khususnya identifikasi pasien dan menjaga keamanan obat telah tersedia dan tercukupi. Dalam sasaran keselamatan pasien dari aspek Komitmen petugas merupakan adanya sikap kesediaan yang berasal dari petugas yang dalam hal ini yaitu perawat dan tim keselamatan pasien rumah sakit untuk melaksanakan aturan yang ada di rumah sakit dalam melaksanakan tugasnya.Dalam wawancara mendalam kepala perawat menyatakan perawat pelaksana yang bertugas di unit rawat inap sudah cukup berkomitmen dengan pekerjaannya dan juga patuh terhadap peraturan yang ada, namun dalam prakteknya perawat tidak selalu melaksanakan identifikasi pasien sesuai SOP.Pasien yang cukup banyak membuat perawat pelaksana sibuk dan megabaikan peraturan yang seharusnya diterapkan contohnya seperti pada saat mengindentifikasi pasien, perawat tidak menanyakan nama pasien karena merasa telah mengingat dengan jelas pasien tersebut dan beralasan apabila menanyakan nama pasien terus menurus hanya akan mengganggu

pasien dan menghabiskan waktu.identifikasi pasien, gelang identitas pasien sangat diperlukan, gelang tersebut terdapat 4 jenis, gelang warna pink untuk pasien perempuan, gelang warna biru untuk pasien laki laki, gelang warna merah untuk pasien yang memiliki riwayat alergi, gelang warna kuning untuk pasien yang memiliki resiko jatuh.Selain gelang identitas terdapat juga rekam medik pasien, data pasien, serta form pelaporan insiden identifikasi pasien. Sedangkan dalam sasaran keselamatan pasien dari aspek kemanan obat yang perlu diwaspadai telah tersedia label khusus obat high alert, lemari khusus obat high alert, lemari khusus elektrolit konsentrat dan form pelaporan insiden keamanan obat. Sarana dan prasana identifikasi pasien tersedia gelang identitas berwarna merah muda, biru, kuning dan merah, rekam medik dan form pelaporan. Dalam menjaga keamanan obat tersedia label obat, lemari obat terpisah dan form pelaporan. Ketersediaan sarana dan prasarana merupakan hal yang sangat penting dalam mendukung pelaksanaan sasaran keselamatan pasien.

keselamatan pasien di rumah sakit untuk menjaga pasien dari suatu kecelakaan yang tidak di inginkan selama pasien tersebut berada di rumah sakit oleh karena itu budaya keselamatan pasien harus di jalankan di RS. Berdasarkan kepatuhan perawat dalam meletakkan tanda pencegahan jatuh (label segitiga kuning/ merah) di papan tempat tidur diketahui bahwa sebagian besar responden 
patuh meletakkan tanda pencegahan jatuh (label segitiga kuning/ merah) di papan tempat tidur Untuk mengurangi jumlah pasien jatuh sebaiknya para petugas di rumah sakit berkolaborasi untuk memberikan pelayanan yang lebih baik kepada pasien dan melaksanakan tindakan sesuai dengan SOP selain itu sasaran keselamatan Komunikasi efektif yang tepat waktu, akurat, lengkap jelas dan dipahami oleh pasien akan mengurangi kesalahan dan dapat meningkatkan keselamatan pasien. Komunikasi dapat berbentuk lisan dan tertulis. Komunikasi yang mudah terjadi kesalahan kebanyakan terjadi pada saat perintah diberikan secara lisan atau melalui telepon. Agar informasi yang disampaikan oleh perawat ke dokter dapat akurat dan tepat, dalam rangka pengambilan keputusan terhadap situasi klinis yang dihadapi pasien, dapat menggunakan standarisasi komunikasi melalui metode Situation Background Assessment Recommendation (SBAR).

\section{Penutup}

Sasaran keselamatan pasien meliputi tercapainya hal-hal sebagai berikut: 1) Ketepatan identifikasi pasien; 2) Peningkatan komunikasi yang efektif; 3) Peningkatan keamanan obat-obatan yang harus diwaspadai; 4) Kepastian lokasi pembedahan pada pasien yang benar; 5) Pengurangan risiko infeksi terkait pelayanan kesehatan; 6) Pengurangan risiko cedera pasien akibat terjatuh. Maksud dari sasaran keselamatan pasien adalah mendorong perbaikan spesifik dalam keselamatan pasien yang menyoroti bidang-bidang bermasalah dalam perawatan kesehatan, memberikan bukti dan solusi hasil konsensus yang berdasarkan nasihat para pakar.

Isu keselamatan pasien melahirkan paradigma baru tentang mutu pelayanan. Mutu pelyanan yang baik saja tidak cukup berarti bagi pasien tanpa memperhatikan bagaimana derajat unsur resiko dan keselamatan yang diterima oleh pasien. Tinggi rendahnya mutu sebanding dengan tingkat ketersediaan fasilitas pelayanan, untuk mencapai keseimbazngan terbaik antara risiko dan manfaat keselamatan yang diterima oleh pasien. Dalam hal ini rumah sakit melaksanakan program-program mutu dan keselamatan pasien. Keselamatan pasien rumah sakit adalah suatu sistem dimana rumah sakit membuat asuhan pasien lebih aman dengan mencegah terjadinya cedera yang disebabkan oleh 
kesalahan akibat melaksanakan suatu tindakan atau tidak mengambil tindakan yang seharusnya diambil.

Salah satu prinsip pelayanan kesehatan adalah menyelamatkan pasien dengan prosedur dan tindakan yang aman dan tidak membahayakan pasien maupun petugas pemberi pelayanan kesehatan. Setiap fasilitas layanan kesehatan harus selalu menjaga keamanan proses pelayanan kesehatannya guna menghindari terjadinya kesalahan medis (medical error) yang bisa berpengaruh terhadap kualitas pelayanan kesehatan.

\section{Daftar pustaka}

1. Simamora, R. H. (2018). Buku ajar keselamatan pasien melalui timbang terima pasien berbasis komunikasi efektif :

SBAR. Medan: USUpress

2. Simamora, R. H. (2020). Learning of Patient Identification in Patient Safety Programs Through Clinical Preceptor Models. Medico Legal Update, 20(3), 553-556

3. Neri, R. A, dkk. (2018). Analisa Pelaksanaan Sasaran Keselamatan Pasien di Rawat Inap Rumah Sakit Umum Daerah Padang Pariaman. Jurnal.fk.unand.ac.id

4. Sakinah , Syifa dkk. (2017). ANALISIS SASARAN KESELAMATAN PASIEN DILIHAT DARI ASPEK PELAKSANAAN IDENTIFIKASI PASIEN DAN KEAMANAN OBAT DI RS KEPRESIDENAN RSPAD GATOT SOEBROTO JAKARTA. JURNAL KESEHATAN MASYARAKAT (eJournal). Volume 5 Nomor (4)

5. Nurul Hidayatul Ulumiyah. (2018). MENINGKATKAN MUTU PELAYANAN KESEHATAN DENGAN PENERAPAN UPAYA KESELAMATAN PASIEN DIPUSKESMAS. Jurnal Administrasi Kesehatan Indonesia Volume $6 \mathrm{No}(2)$ 
6. Ahmad Ahid Mudayana.2012.PERAN ASPEK ETIKA TENAGA MEDIS DALAM PENERAPAN BUDAYA KESELAMATAN PASIEN DI RUMAH SAKIT. Jurnal kesehatan masyarakat universitas ahmad dahlan yogyakarta.Volume 4 nomor (2)

7. Ultaria S, Tio Dora,dkk. (2017) . GAMBARAN BUDAYA KESELAMATAN PASIEN DI RS ROEMANI MUHAMADDIYAH SEMARANG. JURNAL KESEHATAN MASYARAKAT (e-Journal) Volume 5, Nomor(1)

8. Isnaini , mahya nur,dkk (2014).PENGALAMAN PERAWAT PELAKSANA DALAM MENERAPKAN KESELAMATAN PASIEN . Jurnal Managemen Keperawatan . Volume 2, Nomor ( 1 )

9. Surahmat,Raden,dkk.(2017).HUBUNGAN SUPERVISI DENGAN IMPLEMENTASI SASARAN KESELAMATAN PASIEN DI RUMAH SAKIT MUHAMMADIYAH PALEMBANG.jurnal fakultas keperawatan Unand.Volume 2,Nomor (1)

10. Cecep Triwibowo \& sulhah Yuliawati. 2016. Handover sebagai upaya peningkatan keselamatan pasien. Jurnal keperawatan Soedirman.Volume 11 Nomor(2)

11. Pambudi, Yohanes David Wahyu,dkk. (2018) FAKTORFAKTOR YANG MEMPENGARUHI PERAWAT DALAM PENERAPAN 6 SKP (SASARAN KESELAMATAN PASIEN) PADA AKREDITASI JCI (JOINT COMMISSION INTERNATIONAL) DI RUANG RAWAT INAP RUMAH SAKIT PANTI WALUYA MALANG. Nursing News Volume 3, Nomor (1)

12. Fatmawati, Astar \& Hasmin Tamsah, dkk. ( 2012 ). PENGARUH PELAYANAN SASARAN KESELAMATAN ASUHAN KEPERAWATAN TERHADAP KEPUASAN PASIEN DI PUSKESMAS. JOURNAL OF MANAGEMENT Volume 1 Nomor ( 2 ) 